\title{
Structural Behavior of Hair Fiber Reinforced Concrete Beams
}

\author{
Sayed Javid Azimi \\ Ministry of Higher Education AfghanistanHigher Education Development Program (HEDP) \\ Faculty of Civil Engineering, University Takhar, Afghanistan
}

\begin{abstract}
This paper presents the structure properties of hair fiber reinforced concrete beams (HF-RCB). The main objective of this research was to investigate the potential advantages of hair fiber for improving the structure properties of reinforced concrete beams. Furthermore, the potential of hair fiber as part shear reinforcement by increasing the stirrups spacing of beams considered and verified the structure applicability of the proposed materials. This research carried out by two methods experimental and consequently numerical modeling. The experimental work focused on two beams. First beam constructed with full shear reinforcement and without fiber ( $\mathrm{SI}=0 \%$ and with $\mathrm{V}_{\mathrm{f}}=0 \%$,) denoted as a control beam. Meanwhile, one more beam with full shear reinforcement $(\mathrm{SI}=0 \%)$ and with fiber volume fraction of $\mathrm{V}_{\mathrm{f}}=1 \%$ constructed respectively. The experimental work has been considered four point flexural test consequently numerical modeling with finite element method (FEM) software Abaqus for calibration and validation of experimental result considered. First, sensitivity analysis (mesh and time) continued up to acquire the best correlation with experimental results. Then, the experiment results of beams were used, for calibration in FEM modeling investigation. Once satisfactory results obtained parametric study on key parameters with three shear reinforcement arrangement $(\mathrm{SI}=0 \%, \mathrm{SI}=$ $50 \%$ and $\mathrm{SI}=100 \%)$ and together with six volume fraction $\left(\mathrm{V}_{\mathrm{f}}=0 \%, \mathrm{~V}_{\mathrm{f}}=0.5 \%, \mathrm{~V}_{\mathrm{f}}=1 \%, \mathrm{~V}_{\mathrm{f}}=1.5 \%, \mathrm{~V}_{\mathrm{f}}=2\right.$ $\%$ and $\mathrm{V}_{\mathrm{f}}=2.5 \%$ ) of hair fiber were carried out. The result comparison showed a good agreement between the experiment test and nonlinear finite element analysis NLFEA results. Generally this investigation demonstrated significant improvement on structure properties of beams by addition of hair fiber.
\end{abstract}

Keywords - Hair fiber, HF-RCB, Shear strength, ductility, load carrying capacity, mode of failure

\section{INTRODUCTION}

Concrete is a well-known construction material today (Abbas, 2012). It is composed of mainly water, cement, aggregate, and as well as often additive like fly ash, and silica fume are included into the mixture to acquire the desired physical properties (Altun, 2013). Concrete is weak in tension and has brittle characteristics. Since concrete is weak in tension hence some measures must be adopted to overcome this deficiency. Therefore, steel reinforcement, and different types of fibbers are added within concrete structures to improve the tensile strength of concrete (Carmona, 2013). Hence, Fibers have been used as reinforcement since ancient times as stated (Arisoy, 2002). The main challenge for structural engineers is to provide sustainable, environmental friendly and financially feasible structures to the society. Finding new materials that can fulfill these requirements is a must (Ashour, 1992; Bischoff,2 003; Deka, 2013). Most of researcher agreed for a major reason in the performance of fiber into concrete structures;(1) Improve the tensile or flexural strength; (2) Improve the shear strength (3) Improve the impact strength, (4) Improve flexibility, (5) Improve the Ductility, (6) Control cracking and change mode of failure from shear to more ductile one (Lok, 1998 and Merta, 2013). Historically, horse-hair was used in mortar and straw in mud bricks .Since biblical times fibers were used in cementing construction materials in the form of straw and horse hair (Jiang, 2003). Horse hair is used as a fiber reinforcing material in concrete to study its effects on the shear strength, compressive, crushing, flexural strength and cracking control to economies concrete and to reduce environmental problems created by the decomposition of Horse hairs(Lewis, 1979). As stated Cucchiara, 2004, Horse hair has more tensile strength than human hair and concept of using hair as fiber reinforcement and heat resistant material in concrete is not new. However, various types of fibers are available but the most economic and envoirementl friendly fiber in our country is hair fiber (human and animals hair). Hence, Horse hair widely exists in all part of Afghanistan, especially in Northern provinces. It is consumed as a wasted material; if the usage of horse hair into concrete be accustomed in Afghanistan we will have increment of economics, and saving the environment. Hence, the present research aimed to study the behaviour of hair fiber added by volume fraction in reinforced concrete structure and its potential benefits in enhancing ductility and load carrying capacity. 


\section{METHODOLOGY}

\section{A. Preparation of reinforced concrete beams for testing.}

The present research centres on both experimental work and numerical modelling. The experimental work focuses on the addition of horse hair fiber in reinforced concrete beams under laboratory conditions. The results obtained from the experimental work were used to calibrate the numerical model before further parametric studies are carried out.

Table 1 lists three sets of concrete mixture proportions for five beams. Hair fibres included in the mixtures are $30 \mathrm{~mm}$ of length as shown in Fig. 1. The concrete mixture used in the fabrication of all specimens has a slump in the range of $95 \mathrm{~mm}$ to $105 \mathrm{~mm}$.

Table1: mixture of concrete

\begin{tabular}{|l|c|c|}
\hline Ingredients & $\mathbf{K g} / \mathbf{m}^{\mathbf{3}}$ & $\mathbf{K g} / \mathbf{m}^{\mathbf{3}}$ \\
\hline Concrete & Mix 1 & Mix 2 \\
\hline Hair fiber $\left(\mathbf{V}_{\mathbf{f}}=\mathbf{1 \%}\right)$ & 0 & 1 \\
\hline Coarse aggregate & 308 & 308 \\
\hline Fine aggregate(sand) & 848 & 848 \\
\hline W/C ratio & 0.4 & 0.4 \\
\hline Cement & 510 & 510 \\
\hline
\end{tabular}

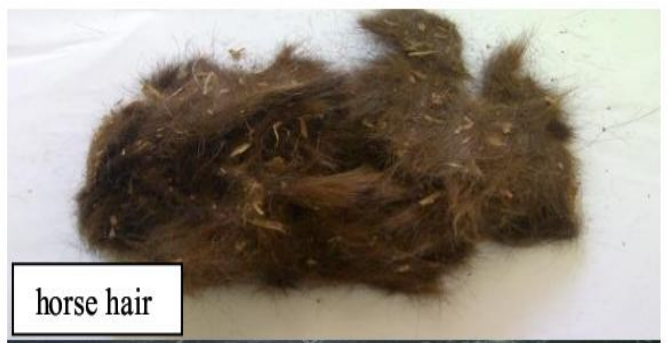

Figure 1: Hair fiber (cut $30 \mathrm{~mm}$ length)

\section{B. Testing.}

Static loading test was conducted using a hydraulic machine under two point loading. The three linear variable differential transducers (LVDT) in the actuator were used to determine the mid-span displacement whilst the load cell indicated the applied. The cracking of the beams was marked by numbering all the cracks and their location. The loading arrangement and reinforcement properties of the beam are shown in Fig. 3 and Fig. 4. The beams were initially designed by Euro code 2 with shear reinforcement less than that is required to cause shear failure. The test was carried out on the 56th day in order to ensure that the RC beams added with Hair were fully hardened.

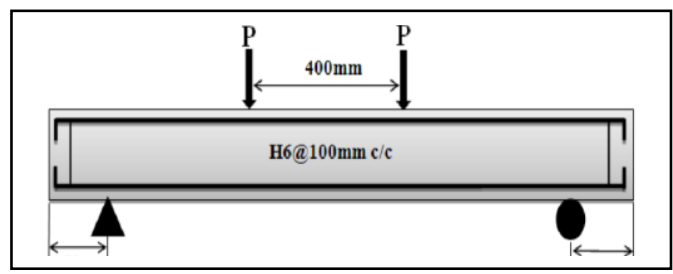

Figurer 2: Loading arrangement and dimensions of the beam

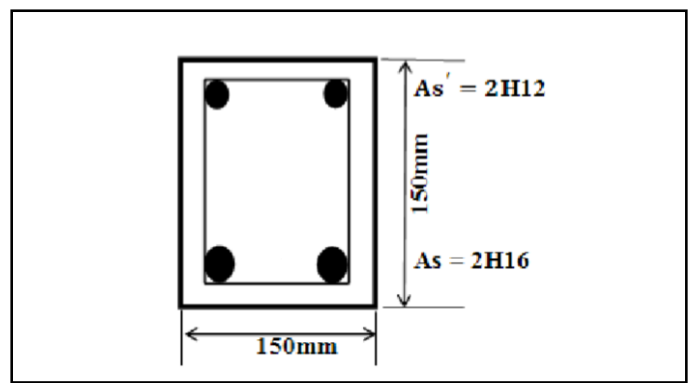

Figure 3: Main reinforcement arrangement $\&$ dimensions of The beam 


\section{Modelling of beam with Abaqus.}

The numerical modelling is accomplished by means of NLFEA built in Abaqus. Figure 3.16 briefly explains the numerical work procedure conducted through Abaqus.

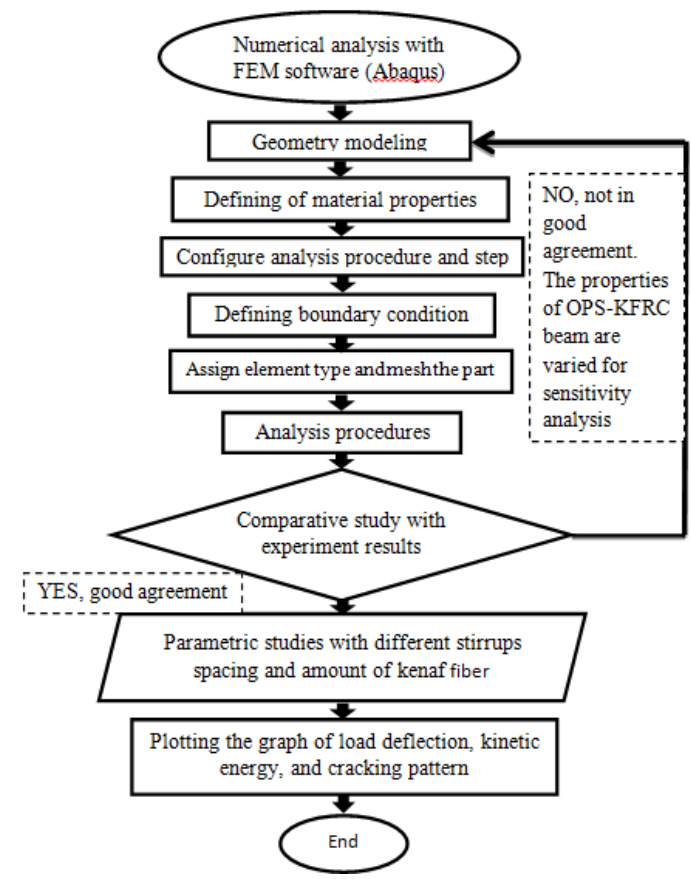

Figure 4: Numerical analysis procedure with FEM software (Abaqus)

the geometry of the beam is modelled similarly to the beam considered in the experimental work created in the part module by entering the dimensions (length, width and height), thickness of the cover, as well as reinforcements. In order to simulate the experimental conditions, steel plates of $10 \mathrm{~mm}$ thickness and $20 \mathrm{~mm}$ width extending across the breadth of the beam were added at the support and loading points. The steel plate for loading points and support point assigned linear elastic property where the cracking is not allowed. This was done to prevent convergence, where the model could become numerically unstable. In order to reduce the duration for the analysing, a half beam (1500 mm long, $150 \mathrm{~mm}$ high and $75 \mathrm{~mm}$ wide) was modelled symmetrically along the z-axis as illustrated in Figure 5.

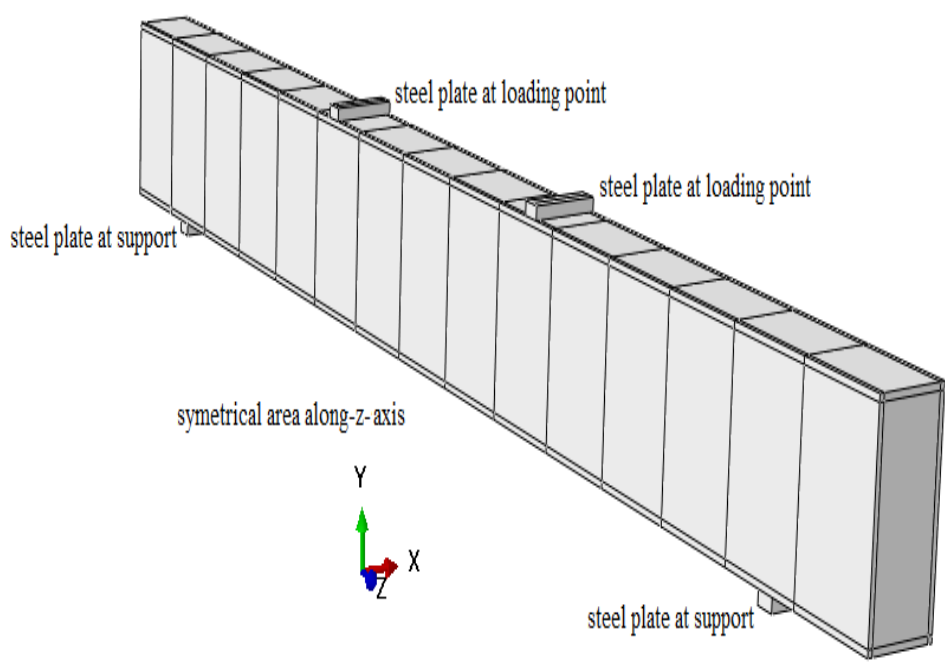

Figure 5: Half of the beam model in Abaqus with defined boundary condition along-z- symmetrical After the geometry model has been constructed, the material properties of RC beam and reinforcement are assigned into brittle cracking concrete model. The effect of the fibres as reinforcement was adopted in the 
tension part of the concrete models, as post peak tensile strain softening or hardening depends on the amount of fibres. Also, the fibres effect on shear response concrete structure considered by using the "shear retention" part of Abaqus concrete model. Shear retention is used to allow for the impact of aggregate interlock and dowel action. After all the aforementioned settings are arranged, the model is then submitted to the analysis procedure. At the calibration stage of this study, numerical modelling is carried out by using beams with $\mathrm{V}_{\mathrm{f}}=0 \%, \mathrm{~V}_{\mathrm{f}}=1$ $\%$ fiber content and full shear reinforcement $\mathrm{SI}=0 \%$. Once an acceptable correlation was obtained, the parametric studies based on two distinct parameters volume fraction of fiber $\left(\mathrm{V}_{\mathrm{f}}\right)$ and stirrups spacing incensement (SI) were performed.

\section{RESULTS AND DISCUSSION}

A. The load-deflection relationships of beams that were acquired in the experimental works were used to calibrate and validate the FE predictions. The modulus of elasticity of $18.5 \mathrm{GPa}$ was used for all beams. A number of sensitivity studies mesh were also performed as shown in Figures 6 and sensitivity of time as shown in Figure 7. This was conducted to correlate experimental results with our finite element model as it is both mesh and time dependent. The mesh adopted has an element size of $15 \mathrm{~mm}$ was selected once the sensitivity analysis mesh and time was performed. By reducing the mesh size to $15 \mathrm{~mm}$ the duration of the analysis of each model increased up to 10 hours. Therefore, the mesh sizing associated with $15 \mathrm{~mm}$ together with T2 were selected it possesses a good correlation with the experimental data.

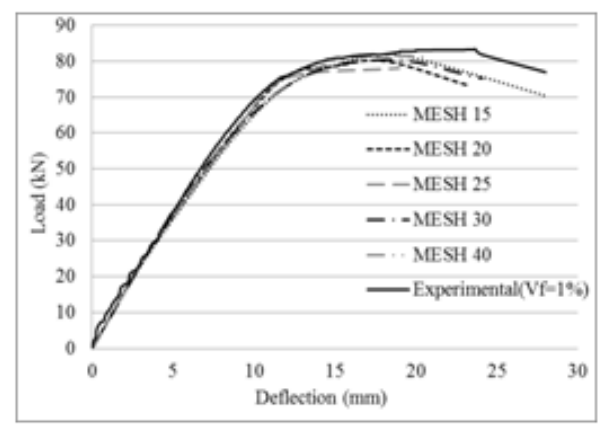

Figure 6: Load-deflection curves for mesh analysis with SI $=0 \%$

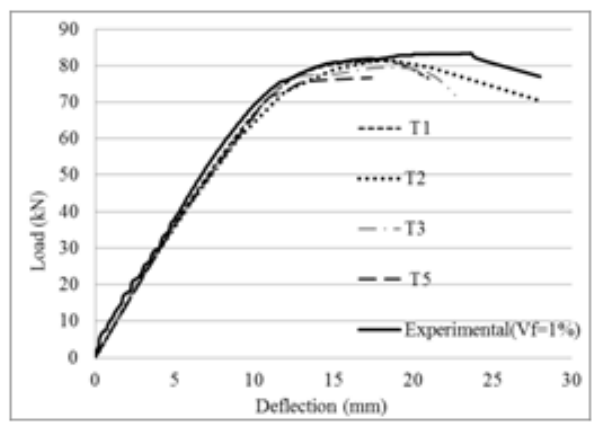

Figure 7: Load-deflection curves for time analysis with SI $=0 \%$

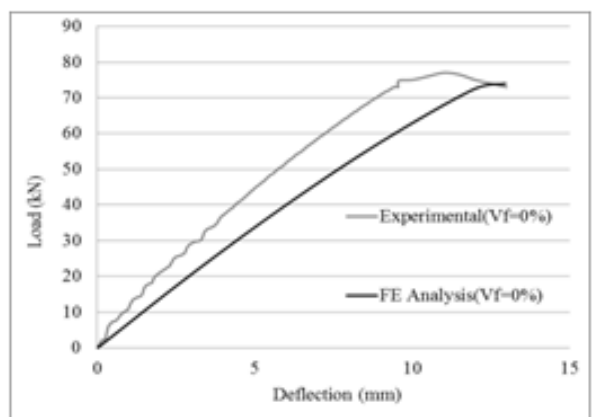

Figure 8: L oad-deflection curve of HF-RC beam with SI $=0 \%$

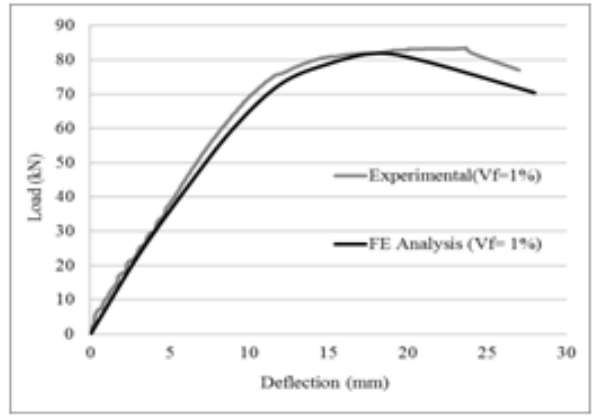

Figure 9: Load-deflection curve of HF-RCB beam with SI $=0 \%$

The failure point on the FE investigation in Abaqus is decided via the kinetic energy of the beam. In present calibration work and following parametric modelling, the failure point is determined based on the sudden high jump in the kinetic energy. The sudden high rise of kinetic energy indicates that the sudden movement of structure which specified the presence of wide cracks within the member which representing the structure was under failure stage. The comparisons between the experimental and numerical results are shown in Figure 8 and Figure 9 with the key parameters summarised in Table 2. It was discovered that load-deflection curves of the FE model results were in good agreement with the experimental results. It is observed that experiment result have stiffer load-deflection curve as compared to FE model with volume fraction of $\mathrm{V}_{\mathrm{f}}=0 \%$. In addition, the beam with fiber volume fraction of $\mathrm{V}_{\mathrm{f}}=1 \%$ correlates better in terms of stiffness and ultimate displacement. A comparison between the experimental and numerical results is presented in Figure 8 and Figure 9 , for both beams without and with fibres denoted by symbols $\left(\mathrm{V}_{\mathrm{f}}=0 \%\right)$ and $\left(\mathrm{V}_{\mathrm{f}}=1 \%\right)$, respectively. The key values are summarised in Table 2. There is good agreement between the two sets of data. 
Table 2: Calibration results summary for beams with full shear reinforcement

\begin{tabular}{|l|l|l|l|l|l|c|}
\hline \multicolumn{1}{|c|}{ Beam } & $\begin{array}{c}\mathbf{P}_{\mathbf{y}} \\
\mathbf{k N}\end{array}$ & $\begin{array}{c}\boldsymbol{\delta}_{\mathbf{y}} \\
\mathbf{m m}\end{array}$ & $\begin{array}{c}\mathbf{P}_{\mathbf{u}} \\
\mathbf{k N}\end{array}$ & $\begin{array}{c}\boldsymbol{\delta}_{\mathbf{u}} \\
\mathbf{m m}\end{array}$ & $\begin{array}{c}\mathbf{P}_{\mathbf{m a}} \\
\mathbf{k N}\end{array}$ & $\boldsymbol{\mu}_{\mathbf{N}} \mathbf{\delta}_{\mathbf{u}} / \boldsymbol{\delta}_{\mathbf{y}}$ \\
\hline EX $\left(\mathbf{V}_{\mathbf{f}}=\mathbf{0} \%\right)$ & 58.0 & 6.9 & 73.0 & 13.0 & 77.0 & 1.8 \\
\hline FE(Vf= 0 \%) & 61.0 & 9.0 & 73.9 & 12.9 & 73.9 & 1.4 \\
\hline EX(Vf= 1 \%) & 69.0 & 9.9 & 70.1 & 28.1 & 84.5 & 2.8 \\
\hline FE (Vf = 1 \%) & 64.5 & 9.0 & 70.4 & 27.9 & 81.9 & 3.1 \\
\hline
\end{tabular}

Following the calibration work, parametric studies are conducted with two broad parameters, Hair

Figure 10(a): Load-deflection curves for HF-RC beams with SI $=100 \%$

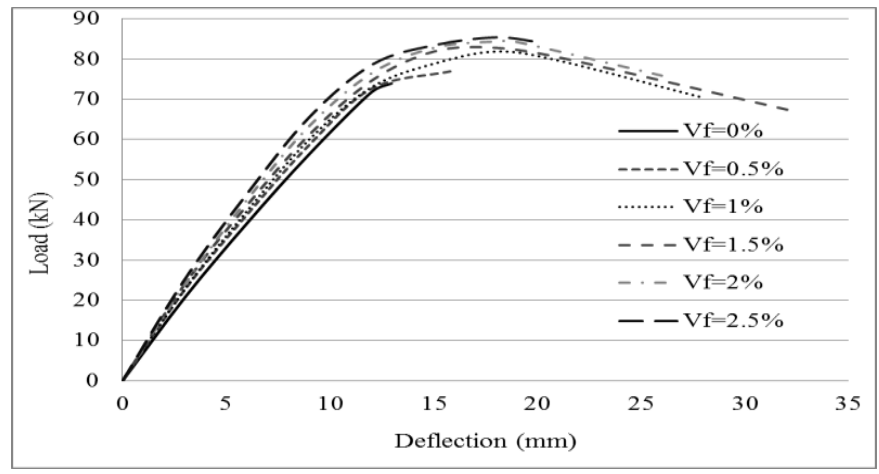

Figure 10(b): Load-deflection curves for HF-RC beams with SI $=100 \%$

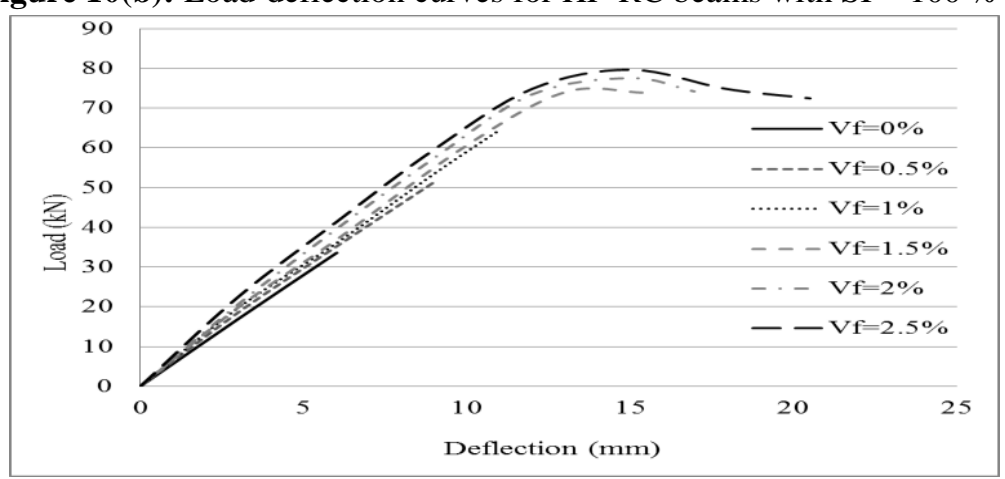

Figure 10(c): Load-deflection curves for HF-RC beams with SI $=100 \%$

fibres volume fraction $\left(\mathrm{V}_{\mathrm{f}}\right)$ and the increasein stirrups spacing $(\mathrm{SI})$. The effects of fibres amount on structural enhancements are studied by six-volume fraction of Hair fibres which are $\mathrm{V}_{\mathrm{f}}=0 \%, \mathrm{~V}_{\mathrm{f}}=0.5 \%, \mathrm{~V}_{\mathrm{f}}=1 \%, \mathrm{~V}_{\mathrm{f}}=$ $1.5 \%, \mathrm{~V}_{\mathrm{f}}=2 \%$ and $\mathrm{V}_{\mathrm{f}}=2.5 \%$ on three stirrups spacing arrangement of SI $=0 \%, \mathrm{SI}=50 \%$ and $\mathrm{SI}=100 \%$ beams which stirrups arrangements with SI $=0 \%$ (full stirrups spacing $=100 \mathrm{~mm}$ ). Furthermore, the beams were modelled with reduced shear reinforcement in order to induce a shear mode of failure. The additions of fibres for improving shear strength of the beam in case of changing the mode of failure from shear to bending are examined. The load-deflection curves for beams with stirrup spacing of SI $=0 \%, \mathrm{SI}=50 \%$ and SI $=100 \%$ are presented in Figure 5.9(a), Figure 5.9(b), and Figure 5.9(c) respectively. The primary load values and their respective deflections are identified and provided in Table 5.4 (a), Table 5.4(b) and Table 5.4(c). In which $\mathrm{P}_{\mathrm{y}}$ represents the load at yield, $\mathrm{P}_{\max }$ represents the maximum load, and $\mathrm{P}_{\mathrm{u}}$ represents the ultimate load, with their corresponding deflections include $\delta_{\mathrm{y}}, \delta_{\max }$ and $\delta_{\mathrm{u}}$. Moreover, the ductility ratio $(\mu)$ is defined as $\mu=\delta_{\mathrm{u}} / \delta_{\mathrm{y}}$. The yield point of all steel calculated based on, offset method that in introduced in ASTM-1035. The offset method implemented based on maximum strain value of the control beam $(0.001)$ which assumes the beams with fiber all yields at the same strain values.he load- deflection curves in Figure 5.9 display that the beam without fibres

Table 3(a): Results summary for parametric studies for beams with SI $=0 \%$ 
failed prematurely suggesting a sudden brittle mode of failure which associated with shear strength

\begin{tabular}{|r|c|c|c|c|c|c|}
\hline $\mathbf{V}_{\mathbf{f}}(\boldsymbol{\%})$ & $\begin{array}{c}\mathbf{P}_{\mathbf{y}} \\
(\mathbf{K N})\end{array}$ & $\begin{array}{c}\boldsymbol{\delta}_{\mathbf{y}} \\
(\mathbf{m m})\end{array}$ & $\begin{array}{c}\mathbf{P}_{\mathbf{u}} \\
(\mathbf{K N})\end{array}$ & $\begin{array}{c}\boldsymbol{\delta}_{\mathbf{u}} \\
(\mathbf{m m})\end{array}$ & $\begin{array}{c}\mathbf{P}_{\max } \\
(\mathbf{K N})\end{array}$ & $\boldsymbol{\mu}_{\mathbf{N}} \boldsymbol{\delta}_{\mathbf{u}} / \boldsymbol{\delta}_{\mathbf{y}}$ \\
\hline $\mathbf{0 \%}$ & 61.00 & 9.00 & 73.96 & 12.97 & 73.96 & 1.44 \\
\hline $\mathbf{0 . 5 0 \%}$ & 63.00 & 9.00 & 77.06 & 15.91 & 77.06 & 1.77 \\
\hline $\mathbf{1 \%}$ & 64.50 & 9.00 & 70.42 & 27.97 & 81.90 & 3.11 \\
\hline $\mathbf{1 . 5 \%}$ & 66.00 & 9.00 & 67.38 & 32.08 & 82.81 & 3.56 \\
\hline $\mathbf{2 \%}$ & 67.50 & 9.00 & 75.91 & 25.99 & 84.40 & 2.89 \\
\hline $\mathbf{2 . 5 0 \%}$ & 69.00 & 9.00 & 84.26 & 20.00 & 85.42 & 2.22 \\
\hline
\end{tabular}

insufficiency. As compared to control beam, the beam with fiber illustrates significant increase in strength, stiffness and ductility that is more vital pertaining for design considerations. Inspection of the load deflection show that by increasing the amount of fiber the stiffness, load at yield $\left(\mathrm{P}_{\mathrm{y}}\right)$, and maximum load $\left(\mathrm{P}_{\max }\right)$ consistently increases. The ductility ratio shows improvement upon the inclusion of fibre up to a certain extent, nonetheless beyond this limit, the ductility behaves otherwise. This is due to the addition of more Hair fiber, as the amount of Hair fiber increases, the beam became stiffer and deflects less which is essentially contributed by the fiber acting as pull-out mechanism and cracks arrestor which cause multiple cracking to the beam. Hence, it is apparent that Hair fiber increased the shear capacity of the beam as the mode of failure changed from shear failure to more bending ductile one. Therefore, the improvement of shear strength due to fibres endorses their possibility to substitute conventional shear reinforcement that in turn suggests that the fibres significantly increase structure properties of HF-RC beam

Table 3(b): Results summary for parametric studies for beams with SI $=0 \%$

\begin{tabular}{|c|c|c|c|c|c|c|}
\hline $\begin{array}{c}\mathbf{V f} \\
(\boldsymbol{\%})\end{array}$ & $\begin{array}{c}\mathbf{P}_{\mathbf{y}} \\
(\mathbf{K N})\end{array}$ & $\begin{array}{c}\boldsymbol{\delta}_{\mathbf{y}} \\
(\mathbf{m m})\end{array}$ & $\begin{array}{c}\mathbf{P}_{\mathbf{u}} \\
(\mathbf{K N})\end{array}$ & $\begin{array}{c}\boldsymbol{\delta}_{\mathbf{u}} \\
(\mathbf{m m})\end{array}$ & $\begin{array}{c}\mathbf{P}_{\mathbf{m a x}} \\
(\mathbf{K N})\end{array}$ & $\boldsymbol{\mu}=\boldsymbol{\delta}_{\mathbf{u}} / \boldsymbol{\delta}_{\mathbf{y}}$ \\
\hline $\mathbf{0 \%}$ & 50.30 & 8.00 & 50.30 & 8.00 & 50.40 & 1.00 \\
\hline $\mathbf{0 . 5 0 \%}$ & 57.80 & 9.20 & 70.90 & 10.60 & 67.44 & 1.15 \\
\hline $\mathbf{1 \%}$ & 61.50 & 9.20 & 79.98 & 16.94 & 78.16 & 1.84 \\
\hline $\mathbf{1 . 5 0 \%}$ & 63.00 & 9.20 & 75.38 & 21.90 & 79.11 & 2.38 \\
\hline $\mathbf{2 \%}$ & 64.50 & 9.20 & 74.48 & 24.93 & 80.49 & 2.71 \\
\hline $\mathbf{2 . 5 0 \%}$ & 66.00 & 9.20 & 80.10 & 20.90 & 81.63 & 2.27 \\
\hline
\end{tabular}

Table 3(c): Results summary for parametric studies for beams with SI $=0 \%$

\begin{tabular}{|c|c|c|c|c|c|c|}
\hline $\mathbf{V}_{\mathbf{f}}(\boldsymbol{\%})$ & $\begin{array}{c}\mathbf{P}_{\mathbf{y}} \\
(\mathbf{K N})\end{array}$ & $\begin{array}{c}\boldsymbol{\delta}_{\mathbf{y}} \\
(\mathbf{m m})\end{array}$ & $\begin{array}{c}\mathbf{P}_{\mathbf{u}} \\
(\mathbf{K N})\end{array}$ & $\begin{array}{c}\boldsymbol{\delta}_{\mathbf{u}} \\
(\mathbf{m m})\end{array}$ & $\begin{array}{c}\mathbf{P}_{\mathbf{m a x}} \\
(\mathbf{K N})\end{array}$ & $\boldsymbol{\mu}=\boldsymbol{\delta}_{\mathbf{u}} / \boldsymbol{\delta}_{\mathbf{y}}$ \\
\hline $\mathbf{0 \%}$ & 33.61 & 6.00 & 33.61 & 6.00 & 33.61 & 1.00 \\
\hline $\mathbf{0 . 5 0 \%}$ & 51.46 & 9.00 & 51.46 & 9.00 & 51.46 & 1.00 \\
\hline $\mathbf{1 \%}$ & 58.60 & 9.40 & 64.50 & 10.90 & 64.50 & 1.16 \\
\hline $\mathbf{1 . 5 0 \%}$ & 60.20 & 9.40 & 73.87 & 15.50 & 74.84 & 1.65 \\
\hline $\mathbf{2 \%}$ & 61.60 & 9.40 & 74.24 & 16.95 & 77.59 & 1.80 \\
\hline $\mathbf{2 . 5 \%}$ & 62.80 & 9.40 & 72.48 & 20.50 & 79.69 & 2.18 \\
\hline
\end{tabular}

\section{B. Principal Strain Contour:}

The principal strain contours of beams at failure phase with SI $=0 \%$, is presented in Figures 11 . In order to observe the contours at failure, the principal strain range is selected between an ultimate tensile strain of 0.001 cracking strain for beams without fibres and 0.006 pull-out strain for HF-RC beams and an ultimate compressive strain of -0.0035 . The grey colour highlighted as tensile failure in principal strain contour of beam representing the area where exceeding the ultimate tensile strain 0.006 for HF-RC and 0.001 for $\mathrm{RC}$ while the region of compressive failure are highlighted in black where the value exceeds the maximum compressive strain. It was found that the failure of beams were considered by tensile cracking at the bottom of middle point of the longest span of beam (at the section where the loads (P) were applied) and top of central support. By associating the 
contour of beams with different percentage of fiber $\left(\mathrm{V}_{\mathrm{f}}\right)$, it is observed cracking formation decreases by increases in fibre amount. Throughout the analysis, only one of these small cracks developed earlier will continue to propagate into a large one. This led to a different location for the single main crack at failure in the beams. Moreover, the pull-out failure region is limited to the narrow zone that situated at the areas of tensile cracking as show for HF-RC beams. Furthermore, it is observed from the cracking pattern the beams without fiber showed high expanded compression zone and diagonal cracking since more fiber added the cracking pattern concentrated at mid-span and showed altering of mode of failure. However, the beams with insufficient amount of fiber did not exhibit cracking pattern more limited at mid-span of the beam that indicates the importance of the amount of fiber for altering the mode of failure. For instance the beams with full shear reinforcement when added fiber up to $\mathrm{V}_{\mathrm{f}}=0.5 \%$ the cracking pattern indicated mode of failure not altered since added fiber up to $\mathrm{V}_{\mathrm{f}}=1 \%$ the cracking pattern concentrated at mid-span and mode of failure properly altered from shear to bending. This suggest that the pull-out mechanism and bridging mechanism of fibres caused to restrained cracks propagation and increased the tensile characteristic of HF-RC structure and prevent from diagonal cracking. Meanwhile the mode of failure of beam with sufficient amount of fiber altered from sudden shear to ductile bending.

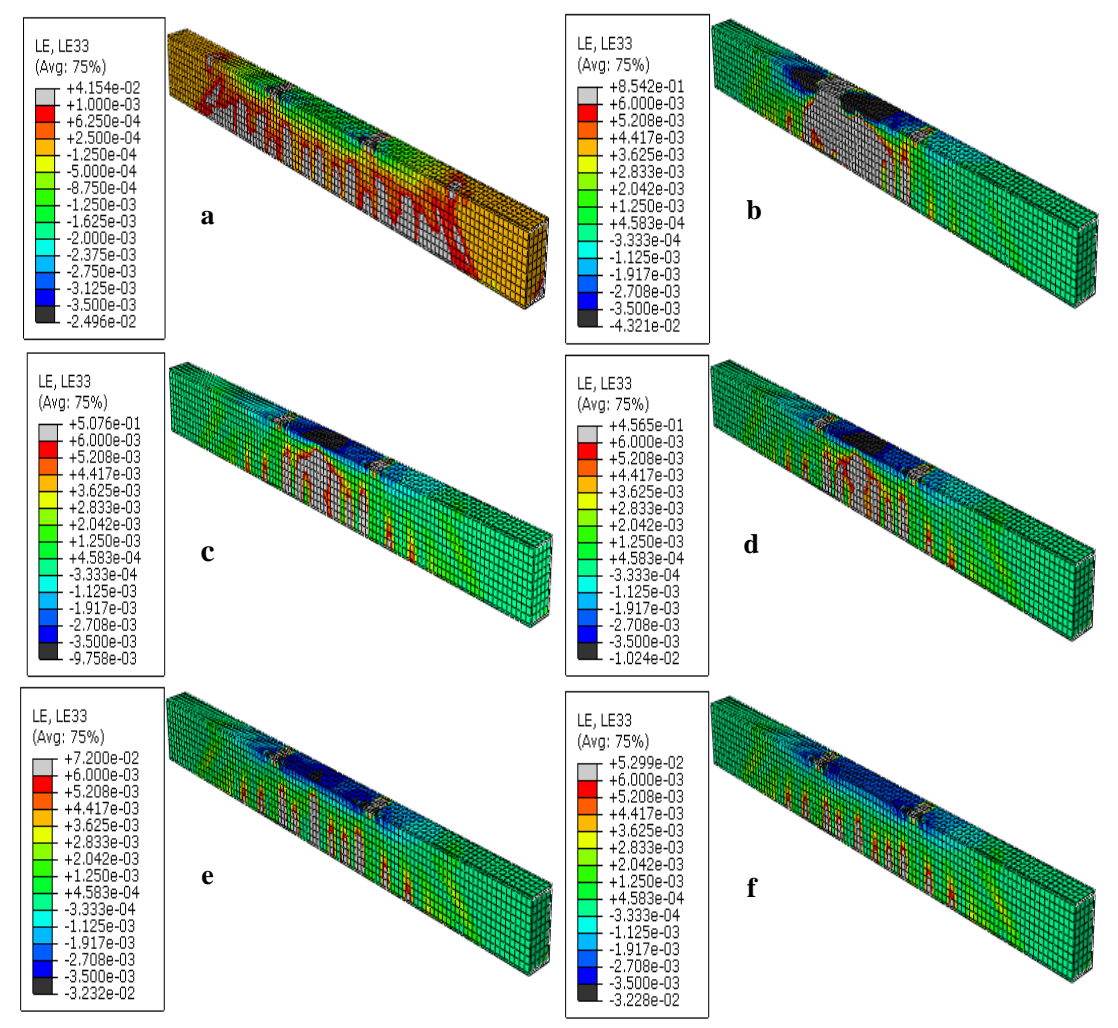

Figure 11: Principal strain vector for beams with $\mathrm{SI}=0 \%$ and (a) $\mathrm{V}_{\mathrm{f}}=0 \%$, (b) $\mathrm{V}_{\mathrm{f}}=0.5 \%$, (c) $\mathrm{V}_{\mathrm{f}}=1 \%$, (d) $\mathrm{V}_{\mathrm{f}}$ $=1.5 \%,(\mathrm{e}) \mathrm{V}_{\mathrm{f}}=2 \%$ and (f) $\mathrm{V}_{\mathrm{f}}=2.5 \%$

\section{Principal Strain Vectors:}

Principal strain vectors of beams at failure are illustrated in Figure 12. The principal strain vector of the control beam is high and covers the whole beam, indicating a crack pattern that is diagonal. The diagonal crack of the beam propagates more when the stirrup spacing is increased as the beam with insufficient amount of fiber is added. The diagonal pattern characterized brittle (shear) mode of failure. It is observed that the addition of fiber changed the mode of failure of beams from shear to bending. It is noteworthy to mention that for beams with reduced shear reinforcement SI $=50 \%$ and SI $=100 \%$, the addition of fibres by up to $\mathrm{V}_{\mathrm{f}}=1 \%$ and $\mathrm{V}_{\mathrm{f}}=$ $1.5 \%$ respectively does not alter the failure mode that still shows the initiation of some shear cracks that can be seen near the support. This reduction in shear reinforcement, when the extra shear reinforcement was reduced, requires higher amounts of fibres in order to limit the crack pattern and alter the failure mode. Since the crack pattern of the beam with fiber is more concentrated in mid-span. Even, the cracking pattern of beams with $\mathrm{SI}=$ $50 \%$ and SI $=100 \%$ and sufficient amount of fiber showed altering of mode of failure. The concentration of failure strains of HF-RC beams is reduced with the increase of fibres amount due to the effect of Hair fibres in 
bridging and restraining cracks. This can be concluded that by observing the principal strain vectors alteration the mode of failure from sudden (shear) to more ductile (bending).
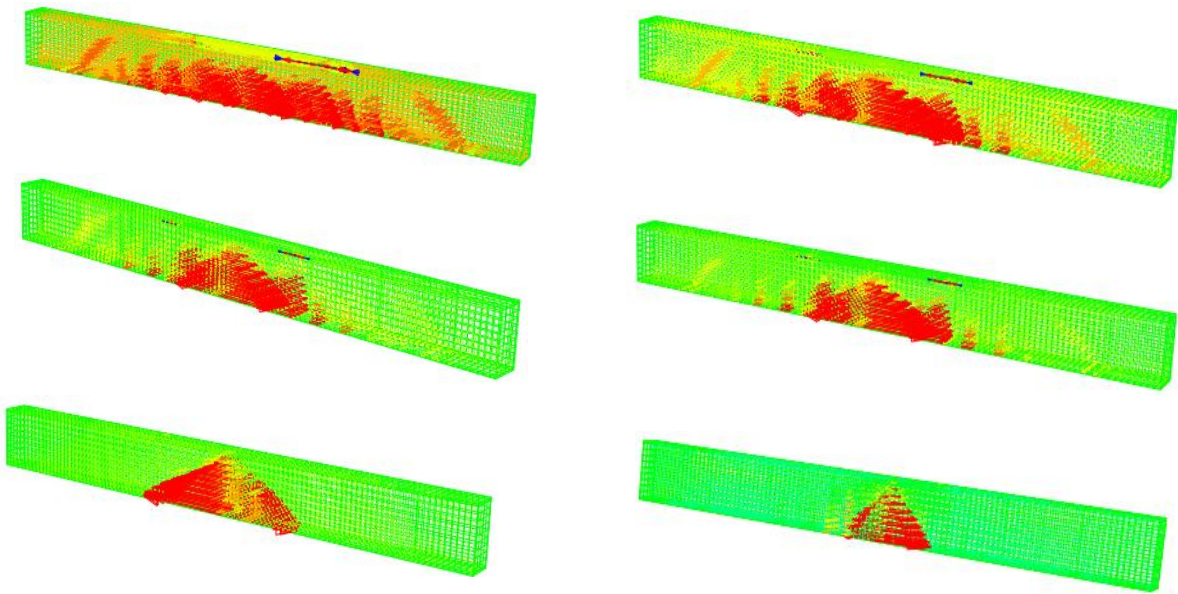

Figure 12: Principal strain vector for beams with $S I=0 \%$ and $(a) V_{f}=0 \%$, (b) $V_{f}=0.5 \%$, (c) $V_{f}=1 \%$, (d) $V_{f}$ $=1.5 \%,(\mathrm{e}) \mathrm{V}_{\mathrm{f}}=2 \%$ and (f) $\mathrm{V}_{\mathrm{f}}=2.5 \%$

It is observed from the cracking patterns the failure mode of beams altered from shear to bending when sufficient amount of fiber added into the beams. This is because, the shear strength of a reinforced concrete beam is directly related to diagonal tensile cracking, since the fiber can transfer the tensile stress across cracks surfaces that are called crack-bridging mechanism hence fiber prevents the excessive diagonal tensile cracking and effectively enhanced the shear strength of RC beams. Moreover, the shift of the failure mode of beams from shear to bending was more closely related to the shear reinforcement arrangement of beams and amount of fiber. The fiber contribution to the shear strength of the beams with full shear reinforcement $(\mathrm{SI}=0 \%)$ and beams with reduced shear reinforcement $(\mathrm{SI}=50 \%$ and SI $=100 \%$ ) was different, thus the mode of failure of beams with full shear reinforcement was altered from shear to bending at $\mathrm{V}_{\mathrm{f}}=1 \%$ even, beams with reduced shear reinforcement $\mathrm{SI}=50 \%$ and $\mathrm{SI}=100 \%$ altered from shear to bending at $\mathrm{V}_{\mathrm{f}}=1.5 \%$ and $\mathrm{V}_{\mathrm{f}}=2 \%$ respectively. This may be the result of extra shear reinforcement take-out from the beams, more fiber needed to restore the same shear strength capability beams. It can be concluded that the fiber showed beneficial contribution to limit cracks and increasing the tensile characteristic of concrete which is expected by the addition of Hair fiber into $\mathrm{RC}$ structures.

\section{Comparative Study of Control Beam Using Non-dimensional Ratios}

In this section, the overall comparison between the beams with various fibres content and stirrups arrangement are made by taking the control beam $\left(\mathrm{V}_{\mathrm{f}}=0 \%\right.$ and $\left.\mathrm{SI}=0 \%\right)$. Normalised value with ductility and energy absorption is by dividing them with associated control beam. Considerations on each normalised value are made to conclude the effectiveness of fibres on mentioned structural response.

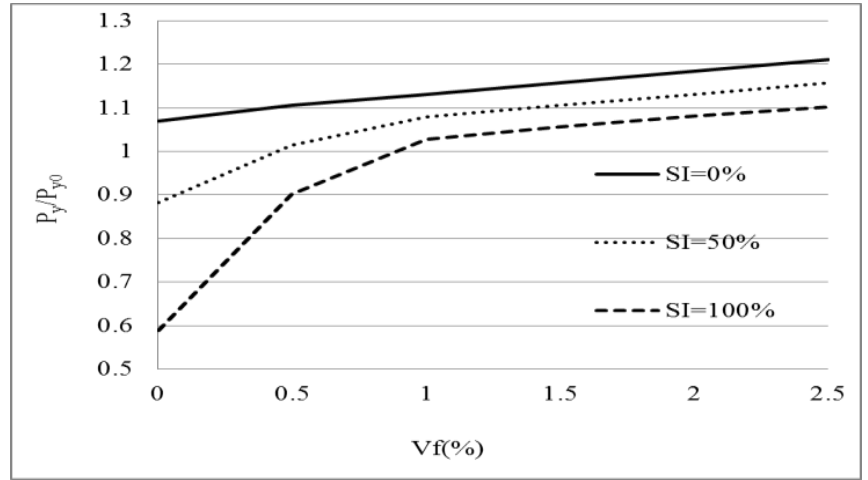

Figure 9: Ratio of maximum load to that of the control specimen ( $\left.\mathrm{SI}=0 \%, \mathrm{~V}_{\mathrm{f}}=0 \%\right)$ against Hair fiber volume fraction graph 


\section{Strength Ratio:}

The ratio of load at yield to the control beam $\left(\mathrm{P}_{\mathrm{y} / \mathrm{P} 0} \mathrm{P}_{\mathrm{y}}\right)$ and load at max to control beam $\left(\mathrm{P}_{\max } / \mathrm{P}_{\max , 0}\right)$ shown in Figure 9 and Figure 10 respectively. Similar trend was observed for the load at max $\left(\mathrm{P}_{\max }\right)$ and load yield $\left(\mathrm{P}_{\mathrm{y}}\right)$ as compared to the control beam. By the the addition of more fibres $\left(\mathrm{V}_{\mathrm{f}}\right)$ both values increased steadily. Beams without fibres and with reduced shear reinforcement $(\mathrm{SI}=50 \%$ and SI $=100 \%)$ showed a decrease in load at max and load at yield ratios as compared to control beam. The fibre act multi-dimensional into the matrix that improves the bond between the matrix and caused to increase the load at yield $\left(\mathrm{P}_{\mathrm{y}}\right)$. Also, upon crack initiation, the fiber act as crack bridging or pull-out mechanism and the occurrence of multiple cracking causes the load at $\max \left(\mathrm{P}_{\max }\right)$ to increase.

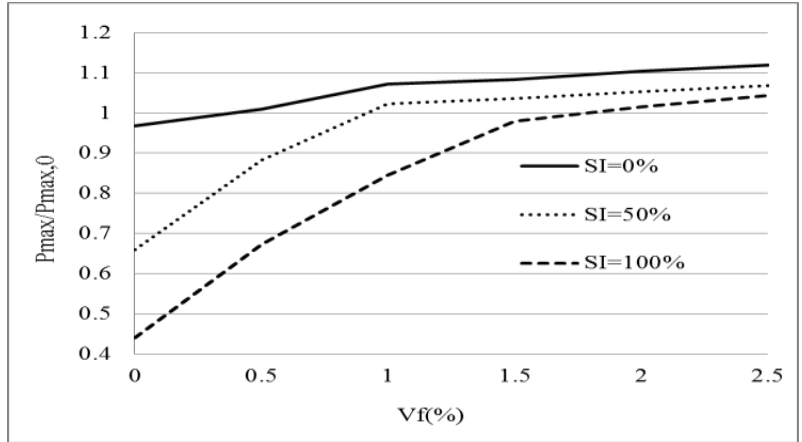

Figure 10: Ratio of yield load to that of the control beam $\left(\mathrm{SI}=0 \%, \mathrm{~V}_{\mathrm{f}}=0 \%\right)$ against Hair fibervolume fraction graph

Adding fibres at $\mathrm{V}_{\mathrm{f}}=0.5 \%$ and at $\mathrm{V}_{\mathrm{f}}=1 \%$ with $\mathrm{SI}=50 \%$ restored the capability of $\mathrm{P}_{\mathrm{y}}$ and $\mathrm{P}_{\max }$ level of the control beam respectively. Meanwhile, the beam with $\mathrm{SI}=100 \%$ at $\mathrm{V}_{\mathrm{f}}=1 \%$ and $\mathrm{V}_{\mathrm{f}}=1.5 \%$ restored the capability of $\mathrm{P}_{\mathrm{y}}$ and $\mathrm{P}_{\max }$ level of the control beam respectively. The highest improvement of $\mathrm{P}_{\mathrm{y}} / \mathrm{P}_{\mathrm{y} 0}$ and $\mathrm{P}_{\max } / \mathrm{P}_{\max , 0}$ ratio was achieved beams with $\mathrm{SI}=0 \%$ at $\mathrm{V}_{\mathrm{f}}=2.5 \%$ up to $12.2 \%$ and $11.2 \%$ respectively. This concludes that the addition of Hair fiber into the mixture considerably enhanced the strength $\left(\mathrm{P}_{\mathrm{y}}\right.$ and $\left.\mathrm{P}_{\max }\right)$ of HF-RC structures.

\section{Ductility Ratio:}

Figure 11 illustrates the results for the ratio of ductility ratio for each beam and that in the control beam plotted against fibre volume fraction on three stirrups spacing arrangement SI $=0 \%, \mathrm{SI}=50 \%$ and $\mathrm{SI}=100 \%$.

There was a considerable increase in the ductility ratio especially for beams with $\mathrm{SI}=0 \%$ at $\mathrm{V}_{\mathrm{f}}=1.5 \%$ up to $212 \%$ as compared to control beam. For beams SI $=50 \%$ and SI $=100 \%$ the maximum ductility enhancements are achieved at $\mathrm{V}_{\mathrm{f}}=2 \%$ and $\mathrm{V}_{\mathrm{f}}=2.5 \%$ respectively.
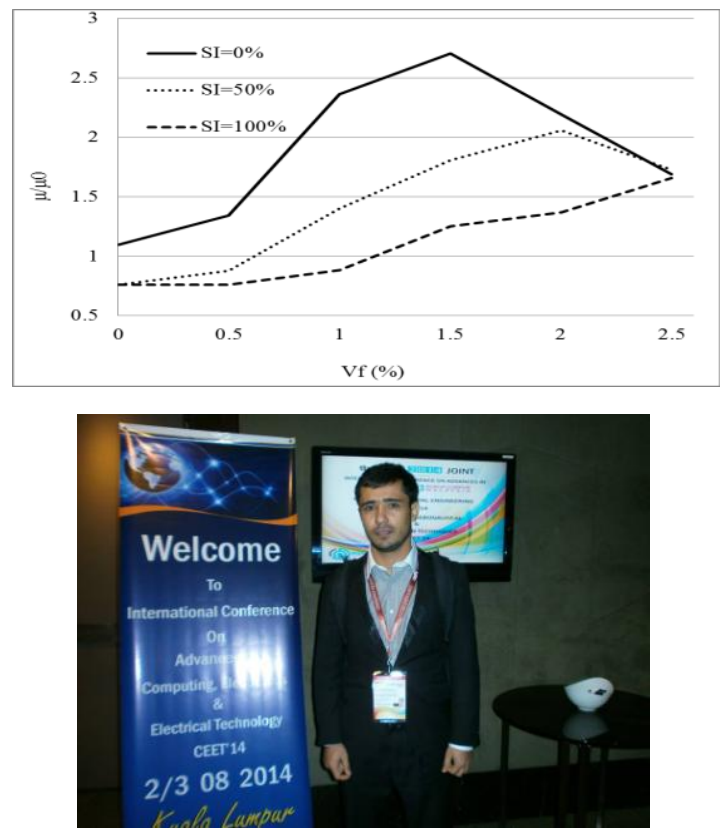

Sayed Javid Azimi, authors of 8 articles in international journals 
Figure 11: Ratio of ductility ratio to that of the control beam $\left(\mathrm{SI}=0 \%, \mathrm{~V}_{\mathrm{f}}=0 \%\right)$ against Hair fiber volume fraction graph

The ductility trend shows improvement for all beams with shear reinforcement arrangement SI $=0 \%$, $\mathrm{SI}=50 \%$ up to a certain limit, beyond that the ductility dropped. The optimum amount of fiber was found to be $\mathrm{V}_{\mathrm{f}}=1.5 \%$ and $\mathrm{V}_{\mathrm{f}}=2 \%$ with $\mathrm{SI}=0 \%$ and with $\mathrm{SI}=50 \%$ respectively. The beams with SI $=100 \%$ the ductility consistently increased by increasing the amount of fiber. This is due to the shear reinforcement takenout from the beam. It is observed, that the ductility ratio decreases when the shear reinforcement reduced from the beams. As the shear reinforcement reduced, a high amount of fibres was needed for achieving the same capability of ductility. It was found that when shear reinforcement spacing increased from the beam up to $50 \%$ and $100 \%$, with addition of $\mathrm{V}_{\mathrm{f}}=1 \%$ and $\mathrm{V}_{\mathrm{f}}=1.5 \%$ the same capacity of ductility with control beam was restored. It indicates that the improvements in ductility are reduced when more than optimum amounts of fibres are added. This can be explained as effectiveness of fibres' in bridging cracks and limiting their opening. It was observed, crack propagation was delayed leading to enhanced ductility of the HF-RCB structures as more fiber content added to the beam, caused the became stiffer and result in failure at small amount of deformation as explained by Syed Mohsin (2012). These findings obtained suggest that incorporating optimum amount of Hair fibres into HF-RC mixture significantly improved the ductility of the structures that in turn desirable in design consideration.

\section{CONCLUSION}

It can be concluded; horse hair fiber showed good compatibility in order to improve the structure properties of $\mathrm{RC}$ beams. Thus, fiber with crack-bridging mechanism or pull-out mechanism restrained the crack opening and increased the strength $\left(\mathrm{P}_{\mathrm{y}}\right.$ and $\left.\mathrm{P}_{\max }\right)$ and as well as increased the ductility up to certain limit. In addition, Hair fibres were efficient for improving the tensile strength of $\mathrm{RC}$ to prevent from diagonal-tension cracking and caused to change the mode of failure of $\mathrm{RC}$ beams from shear to bending. Hence, it is clarified that hair fiber with adequate amount could increase the shear capacity of beam as the mode of failure of beam changed from shear to bending. Therefore, this is confirmed that by addition of a proper amount of Hair fiber possible to reduce the amount of shear reinforcement from HF-RC beams. It is highly recommended to use horse hair fiber with an adequate amount into $\mathrm{RC}$ structure for producing economic concrete structure and improving the structure properties of RC beams.

\section{ACKNOWLEDGMENT}

This project is supported by Ministry Higher Education of Afghanistan under HEDP grant. Sayed Javid Azimi wishes to thank MOHE of Afghanistan, because of funding and supporting to successfully carry out this research.

\section{REFERENCES}

[1] Carmona, S., Aguado, A., and Molins, C. 2013. Characterization of the properties of steel fiber reinforced concrete by means of the generalized Barcelona test. Construction and Building Materials. 48: 592-600.

[2] Abbas, A.A., Syed Mohsin, S.M. and Cotsovos, D.M. 2012. Steel-fibre-reinforced concrete beams under cyclic loads. Universidade do Minho.

[3] Altun, F., and Aktaş, B. 2013. Investigation of reinforced concrete beams behavior of steel fiber added lightweight concrete. Construction and Building Materials. 38:

[4] Arisoy, B. 2002. Development and fracture evaluation of high performance fiber reinforced lightweight concrete (Ph.D.).

[5] Ashour, S. A., Hasanain, G. S., and Wafa, F. F. 1992. Shear behavior of high-strength fiber reinforced concrete beams. ACI Structural Journal 89(2).

[6] Bischoff, P. H. 2003. Tension stiffening and cracking of steel fiber-reinforced concrete. Journal of materials in civil engineering. 15(2):174-182.

[7] Cucchiara, C., La Mendola, L., and Papia, M. 2004. Effectiveness of stirrups and steel fibres as shear reinforcement. Cement and Concrete Composites. 26(7):777-

[8] Carmona, S., Aguado, A., and Molins, C. 2013. Characterization of the properties of steel fiber reinforced concrete by means of the generalized Barcelona test. Construction and Building Materials. 48: 592-600.

[9] Jiang, L. 2003. Strain-hardening behavior of fiber reinforced concrete.

[10] Lewis, G., and Premalal, M. 1979. Natural vegetable fibres as reinforcement in cement sheets. Magazine of Concrete Research. 31(107): 104-108.

[11] Lin, Z., and Li, V. C. 1997. Crack bridging in fiber reinforced cementitious composites with sliphardening interfaces. Journal of the Mechanics and Physics of Solids. 45(5): 763-787.

[12] Lok, T. S., and Pei, J. S. (1998). Flexural behavior of steel fiber reinforced concrete. Journal of Materials in Civil Engineering. 10(2): 86-97 